\title{
2019 revised algorithm for the management of knee osteoarthritis: the Southeast Asian viewpoint
}

\author{
Swan Sim Yeap ${ }^{1} \cdot$ Aree Tanavalee $^{2} \cdot$ Emmanuel C. Perez $^{3} \cdot$ Maw Pin Tan $^{4,5} \cdot$ Bernadette Heizel M. Reyes $^{6}$. \\ Joon Kiong Lee ${ }^{7}$. Mohd Yahaya Norhamdan ${ }^{8}$ Evan S. Vista ${ }^{9}$. Wai Sin Chan ${ }^{10}$. Sy Bui Cong ${ }^{11}$. \\ Pham Thi Thanh Tam ${ }^{12} \cdot$ Jean-Marc Kaufman ${ }^{13} \cdot$ Jean-Yves Reginster ${ }^{14,15,16} \cdot$ Nicola Veronese $^{17}$ (1) $\cdot$ Ester Penserga $^{18}$
}

Received: 24 February 2021 / Accepted: 11 March 2021 / Published online: 28 March 2021

(c) The Author(s) 2021

\begin{abstract}
Background Since 2014, the European Society for Clinical and Economic Aspects of Osteoporosis, Osteoarthritis and Musculoskeletal Diseases (ESCEO) algorithm for the management of knee osteoarthritis (OA) is available worldwide.

Aim Based on this document, a Southeast Asia Working Group (SEAWG) wished to see how the new ESCEO algorithm developed in 2019 was perceived by Southeast Asian experts and how it was integrated into their clinical practice.

Methods A SEAWG was set up between members of the international ESCEO task force and a group of Southeast Asian experts.

Results Non-pharmacological management should always be combined with pharmacological management. In step 1, symptomatic slow-acting drugs for osteoarthritis are the main background therapy, for which high-quality evidence is available only for the formulations of patented crystalline glucosamine sulfate and chondroitin sulfate. In step 2, oral NSAIDs are a useful option, considering the cardiovascular/renal/gastrointestinal profiles of the individual patient. Intra-articular hyaluronic acid and corticosteroids are a possible alternative to oral NSAIDs, but limited evidence is available. If steps 1 and 2 do not give adequate relief of symptoms, tramadol can be used, but its safety is debated. In general, the indications of the ESCEO algorithm are important in Southeast Asian countries, but the reimbursement criteria of local health systems are an important aspect for adherence to the ESCEO algorithm.

Conclusion This guidance provides evidence-based and easy-to-follow advice on how to establish a treatment algorithm in knee OA, for practical implementation in clinical practice in Southeast Asian countries.
\end{abstract}

Keywords Knee osteoartrhitis $\cdot$ Patented crystalline glucosamine sulfate $\cdot$ Symptomatic slow-acting drugs for osteoarthritis · Algorithm

\section{Introduction}

Osteoarthritis (OA) is one of the most common joint diseases in older people, mainly characterized by joint pain and stiffness with deep consequences on functional decline/disability and loss in quality of life $[1,2]$. Knee OA is the most common localization within the symptomatic form affecting more than 250 million people worldwide [3]. Knee OA is ranked among the most common causes of global disability in terms of Disability-Adjusted Life Years (DALY) and poor quality of life [4-6].

Nicola Veronese

nicola.veronese@unipa.it

Extended author information available on the last page of the article
In 2014, the European Society for Clinical and Economic Aspects of Osteoporosis, Osteoarthritis and Musculoskeletal Diseases (ESCEO) published some recommendations for the management of knee OA, developing a treatment algorithm that may give practical guidance for the prioritization of interventions and guiding physicians through progressive steps [7]. However, since the publication of the 2014 algorithm, new research has become available, with a particular attention to the safety of many medications commonly used to treat knee OA [8-11]. In 2016, as new observational data regarding drug safety became available, an update to the ESCEO algorithm was published [12].

Therefore, in 2019, a new algorithm [13] was published taking into account the recent evidence on efficacy and safety of medications commonly used for knee OA and 
the GRADE (Grading of Recommendations Assessment, Development and Evaluation) process was added, to better highlight the evidence used in the algorithm in a transparent and systematic way [14]. Since 2014, the ESCEO algorithm has been well-received worldwide and endorsed by many national societies with a consequent translation, adaptation to the local context, and publication in several countries including China, Russia, Central Europe and Southeast Asia [15-20]. For this reason, a working group (WG) was formed between members of the international ESCEO task force (N.V., J.M.K., and J.-Y.R.) and a group of Southeast Asian experts in knee OA (SEAWG) to see how Southeast Asian key opinion leaders perceive this algorithm and how it can be combined, with their own clinical practice, to harmonize and optimize the management of patients with knee OA throughout the world.

\section{Non-pharmacological treatment in the 2019 ESCEO algorithm}

In the 2019 knee OA algorithm, non-pharmacological treatments (information/education; weight loss if overweight; and an exercise program mixing aerobic and strengthening exercises) have a major importance and is supported by a high level of evidence according to GRADE [7, 13, 21], even if the effect of these interventions is limited and their feasibility in the long term is still debated [22]. The Southeast Asian experts, during the workshop, highlighted the importance of non-pharmacological interventions (such as education and weight loss), including the use of Tai-Chi [23] and acupuncture [24] in patients in their clinical practice, even if this evidence for these last two interventions is supported by low quality studies.

\section{Pharmacological treatment in the 2019 ESCEO algorithm}

\section{Step 1: background treatment}

\section{Paracetamol}

Paracetamol (acetaminophen) is widely used for the treatment of knee OA symptoms, even though in 2014 ESCEO reported that this medication has only a small effect on pain and no significant effect on stiffness and physical function in patients with knee OA [25-27]. During 2014-2018, several concerns were available regarding safety over its routine chronic use, due to the increased risk of gastrointestinal (GI), cardiovascular (CV), hepatic and renal adverse events (AEs) [28] and increased mortality [29]. Surprisingly, even if paracetamol is widely used, its mechanism of action is not completely known, even if it is likely to involve cyclo-oxygenase-2 (COX-2) inhibition, particularly when the cellular environment is low in arachidonic acid and peroxides such as in gastrointestinal and cardiovascular systems [30].

Based on this evidence (limited effect and increased risk of AEs), the 2019 ESCEO reccomends that paracetamol should be used only for short periods, as rescue medication when there is the inefficacy of the background therapy and at doses less than $3 \mathrm{~g} /$ day [13].

\section{SYSADOAS}

In both 2014 and 2019 versions of the ESCEO algorithm, Step 1 treatment of knee OA, recommends initiation of background therapy with long-term SYSADOAs (Symptomatic Slow-acting Drugs for Osteoarthritis) [7, 13], even if this class includes several products such as glucosamine, chondroitin, diacerein, and avocado soybean unsaponifiables (ASU), which are supported by varying degrees of clinical efficacy and safety data.

Glucosamine and chondroitin are natural compounds. Glucosamine hydrochloride $(\mathrm{GHCl})$ is obtained by extraction processes and used as a nutraceutical or over-the counter (OTC) products. In contrast, glucosamine sulfate (GS) is a more sophisticated product, which can be obtained only by a proprietary semi-synthetic route and stabilization process and that is used only in the prescription drug product, i.e. patented crystalline glucosamine sulfate (pCGS) [31]. Unfortunately, multiple formulations of GS are available [32], both as prescription-grade products and OTC, with the latter having small/varying amounts of glucosamine. On the contrary, there is extensive literature to suggest that only pCGS, at least at $1,500 \mathrm{mg}$ per day, is able to deliver consistently high glucosamine bioavailability and plasma concentration in humans, which would result in good clinical efficacy [33-40]. Conversely, $\mathrm{GHCl}$ and non-crystalline glucosamine sulfate products (usually consisting of $\mathrm{GHCl}$ with the addition of sodium sulfate to get a "sulfate" labelling) have consistently been shown to be ineffective in the treatment of knee OA [33, 35, 41-44]. A similar discussion can be applied to chondroitin sulfate [45-50].

Based on this scientific evidence, ESCEO specifically recommends the use of pCGS and long-acting chondroitin sulfate products (the latter of which are not available in Southeast Asia) in both versions of 2014 and 2019 of the algorithm [7, 13]. At the same time as the new ESCEO algorithm was released, another respected society, the Osteoarthritis Research Society International (OARSI) also updated their guidelines [51]. A working group recently conveyed by ESCEO examined the similarities and differences between these two guidelines and provided a narrative document to help guide healthcare providers through the complexities of non-surgical 
management of knee OA (reference enclosed to be added) [52]. Whereas many similarities between the two guidelines were observed, ESCEO strongly supports the use of pCGS and chondroitin sulfate, whereas OARSI does not support their use. The main reason for this discrepancy is that the OARSI guidelines, which were mainly prepared in a US-centric perspective, do not recognize the concept of "pharmaceutical-grade" or "prescription-grade" SYSADOAs, such compounds being unavailable on the US soil [51][51].

The judgement of ESCEO is also based on the safety of SYSADOAs. Except for diacerein, several randomized placebo-controlled trials (RCTs) have demonstrated that SYSADOAs are not associated with any increased risk of AEs, both total and specific [11].

With regards to AEs, concerns have been raised regarding the safety of pCGS in patients with diabetes. Glucosamine, in fact, is an amino sugar that might lead to hyperglycemia and insulin resistance by over activating the hexosamine pathway [53]. However, it was already known that, once in plasma, glucosamine "does not go back to glucose", but is directly catabolized and, therefore, no interference with glucose metabolism is expected [54]. This is also supported from the clinical trials' data. At common doses used for OA treatment, pCGS showed no interference with glucose metabolism in normoglycemic subjects and in most subjects with hyperglycemia, impaired insulin sensitivity, prediabetes or diabetes $[41,55]$. In addition, a meta-analysis on the effects of glucosamine on glucose metabolism found that glucosamine, at the usual oral doses used in knee OA patients, is well-tolerated by normal, diabetic, or pre-diabetic patients [56]. In the PROOF trial, a non-significant increase in glycated hemoglobin levels was found in overweight women who received pCGS during the follow-up period $[57,58]$. Thus, the SEAWG recommends to advise caution at the start of treatment with glucosamine in diabetic patients [59].

\section{Topical NSAIDs}

At the last step of step 1 (background therapy), topical nonsteroidal anti-inflammatory drugs (NSAIDS) may be added as cyclic therapy if the patient is still symptomatic. Whilst there is sufficient evidence that these medications are safe [8], their efficacy has been only demonstrated in short-term RCTs and, therefore, more data are needed for giving these medications for longer periods [13]. The most recent algorithm suggested that topical NSAIDs may be used in preference to oral NSAIDs, particularly in frail patients with knee OA, or prior to use of oral NSAIDs. The SEWG was in agreement with the use of topical NSAIDs for the control of persistent pain in knee OA.

\section{Step 2: advanced pharmacological treatment}

If the patient is still suffering from pain or has important limitations in the activities of daily living, step 2 of the updated version of the algorithm will commence. Step 2 consists of two approaches.

The first approach is the use of oral NSAIDs. Based on the literature available, particularly regarding the safety of these medications [10], ESCEO, in the 2019 algorithm, makes a strong recommendation to the use of oral NSAIDs (selective or non-selective) as Step 2 therapy, but only if used intermittently and for as briefly as possible [13]. Moreover, the use of oral NSAIDs should be based on the patient risk profile, taking in consideration cardiovascular, renal, gastrointestinal co-morbidities [13]. Oral NSAIDs, in fact, should be not used in case of clinical forms of cardiovascular (e.g. decompensanted heart failure), renal (e.g. chronic renal failure with a creatinine clearance $<30 \mathrm{ml} / \mathrm{min}$ ) or gastrointestinal (e.g. upper or lower gastrointestinal hemorrhages). When permitted it is important to remember that ESCEO recommended that all NSAIDs should be used at the lowest effective dose for the shortest period of time necessary to control pain [13]. Moreover, when using oral NSAIDs in older people, it is also important to consider the role of drug interaction in the development of adverse drug reaction. Drug-drug interactions (DDIs) in poly-therapy are one of the commonest causes of medication errors in geriatric medicine, with an estimated prevalence of $20-40 \%$ [60]. When talking about oral NSAIDs, a nice study reported that these medications may act on MAP kinase (MAPK) signal transduction pathway in the synovial membrane [61], a pathway that can be affected by the use of other medications [62].

The second part of step 2 consists of the use of intra-articular medications, i.e. hyaluronic acid and corticosteroids. For both these intra-articular products, there is weak evidence that supports the use of hyaluronic acid and corticosteroids in those who cannot take oral NSAIDs. The reasons for this decision are based on inconclusive efficacy, higher risk of AEs when compared to placebo and only having shorterm RCTs supporting the use of these drugs $[9,13]$.

The SEAWG agreed to the judicious use of NSAIDs for acute exacerbation of knee OA with inflammatory component, after considering the patient profile and co-morbid conditions with reference to gastrointestinal, cardiac and renal diseases. The dose of NSAIDs should be the lowest effective dose.

\section{Step 3: last pharmacological treatment}

Last pharmacological options for the severely symptomatic patient are represented by short-term weak opioids. Tramadol may offer good analgesia in knee OA [63, 64], but a recent meta-analysis of the safety of oral opioids used in 
OA found an increased risk of gastrointestinal, central nervous system, and dermatological AEs compared with placebo [65]. For this reason, ESCEO gives only a weak recommendation to the use of short-term weak opioids in Step 3, as the last pharmacological option before surgery [13]. A similar evidence base is available for duloxetine [13].

The SEAWG concurs to the use of low dose weak opioids, such as tramadol, with the needed precaution for their known adverse events of nausea, somnolence and vomiting.

\section{Step 4: end-stage disease management and surgery}

Total knee replacement (TKR) is appropriate when all previous interventions have failed, if the patient is still symptomatic, and, in particular, when a significant loss in quality of life is present [66-68]. However, for symptomatic patients in whom surgery is cotraindicated, the last pharmacological resort could be oral or transdermal opioids [69], which should be prescribed following the guidelines for use of opioid analgesics in the management of non-cancer pain [70].

The SEAWG adds that background physical therapy is to be continued for surgery-averse patients or those where surgery is contraindicated.

\section{Specificities of osteoarthritis management for Southeast Asia}

As declared in the Introduction, the main objective of this paper is to find a consensus between experts from various South-East Asian countries and to offer a reference document which takes into account the national specificities and tries to be also as consensual as possible with the document published by one non-South East Asian respected society.

As a group of Southeast Asian experts in OA management, the SEAWG has carefully reviewed the ESCEO algorithm, including the most recent update of this year, considering it to be almost similar to the clinical practice pathways in several Southeast Asian countries. Therefore, as described in this paper, the WG endorses the principles of the ESCEO algorithm, reaching a consensus regarding recommendations for the stepwise multi-modal treatment of knee OA in Southeast Asia. With this work, of course, we cannot affirm to have included all the guidelines present in Southeast Asia countries and that these are in line to the ESCEO algorithm. Some national countries have indeed, significant differences in their guidelines compared to what is recommended in the ESCEO algorithm (e.g. the use of oral NSAIDs in the first and not in the second step of knee OA management), but that after an extensive discussion among the experts present at the meeting, we reached a formal consensus and the experts co-signing this paper agreed to the ESCEO recommendations.
However, it should be recognized that, in clinical practice, treatment should be based upon the individualized assessment of the patient, considering patients' needs and preferences, the subjective interpretation of the evidence by the physician, and of course, subject to the local availability of a medication. In Southeast Asia, many countries acknowledge the definitive treatment for severe OA to be surgical in the form of TKR and prevention to avoid this late stage is advocated by at least delaying disease progression with SYSADOAs. Not all SYSADOAs are available at pharmacological doses and, in Southeast Asia, may be included only OTC preparations for which the efficacy is still not clarified. Local practices and cultural variations employ traditional healing remedies without large-scale controlled clinical trials. Complementary and alternative remedies in the form of endemic topical and aromatic preparations as well as physical manipulation (e.g. ayurveda or acupuncture) provides symptomatic relief among OA patient sufferers historically, even if limited data are available. These treatment modalities must be taken into consideration when planning out a comprehensive management approach for the patient. Adopting the ESCEO knee OA guidelines is a structured approached that is well-applicable in each of Southeast countries.

Another important point is that the criteria for reimbursement, as well as the organization of the local health care system, significantly vary across Southeast Asian countries and this should be taken into consideration when choosing treatment options. Moreover, in the same country, there may be differences between rural and urban areas, for example, in terms of the availability of different pharmacological agents. Furthermore, not all SYSADOAs are reimbursable by the public health care systems and, in some cases, even if reimbursed, it is only for limited periods. For this specific reason, the SEAWG wish to highlight the importance of healtheconomic studies that should be done locally to increase the rate of reimbursement of pharmacological agents that can be used to reduce OA progression. At this stage, the ESCEO algorithm is mainly based on the scientific and clinical evidence regarding efficacy and safety. [13] However, since the works regarding economic aspects are increasingly recognized as important, a future document including the health economics, with a specific application to the various South East Asian countries, could be an interesting work to be done.

In Southeast Asia, knee OA is a significant problem. For example, in the Philippines, almost 4 million people suffer from this medical condition, but unfortunately it is not considered among those chronic conditions that should be addressed by specific public health programs. For this reason, in 2017, a Philippine National OA Multidisciplinary Program was proposed to treat OA better. This multidisciplinary approach took into consideration the indications and the steps given by the 2019 ESCEO algorithm [13]. The 
application of the Philippine OA Program does not differ in practice from the steps given in the ESCEO at core step and step 1, even if paracetamol is given as background therapy at low doses, In step 2, the WG noted that not all oral or topical NSAIDs are reimbursed by the Philippines health care. Overall, the Philippine experts strongly believe in the concepts of the 2019 ESCEO algorithm, highlighting the importance of education of health care workers and specialty referral for the most appropriate management of knee OA.

In Thailand, a recent consensus (Thai Consensus Conference on Pharmacological Management of Knee OA 2019) was held. The minutes of this meeting are freely available at this website: https://www.thaihipknees.org/information/ manual-and-proceedings-of-the-thai-consensus-conferenceon-pharmacological-management-of-knee-oa-20192/. This consensus involved 69 experts in knee OA and was divided in two main parts, i.e. oral and non-oral/topical medications for knee OA management. Overall, a strong consensus was reached for the use of oral NSAIDs prescribed as the firstline drug for knee OA, even if they should only be used for a short-term period and intermittently, with caution, and the patient's comorbid conditions taken into account, avoiding the concomitant use of paracetamol. This consensus recognized the importance of pCGS (and not OTC products) as first line/background therapy, which should be used continuously (if possible) and without any age restrictions. New research results were presented based on a real-life study using pCGS in Thailand. In the study, 250 Thai older people, with more than 50 years, with grade 2-3 KL knee OA were followed for 24 weeks and treated with $1500 \mathrm{mg} /$ day of pCGS. The results of this study showed that pain scores, as measured by the visual analogue scale significantly improved after treatment with pCGS. In addition, this study also showed a positive effect of pCGS on quality of life (measured with short form 36) and physical performance, as measured with the timed up-and-go test. Despite the observational nature of these data, this study opens up the idea of a possible effect of pCGS on physical function and quality of life.

In Malaysia, knee pain is extremely common and often due to knee OA. In the Community Oriented Program for the Control of Rheumatic Diseases (COPCORD) survey, $14.4 \%$ complained of pain in the joints and/or musculoskeletal pain. The knee site was responsible for about two/ thirds of all complaints pertaining to the joints, and more than half those examined with knee pain had clinical evidence of OA [71]. In this country, knee pain is a common cause of presentation to the general practitioner, with one study showing it to be the 7th most common complaint. Due to the high frequency of knee pain and presumed OA in the community, a Malaysian Clinical Practice Guideline for the Management of OA was first published in 2002, with a second edition in 2013. For the future, the main aim would be to get health economic data assessing the economic burden of OA, and the cost-effectiveness of treatment with SYSADOAs.

Finally, Macau has about 636,000 inhabitants, with a long-expected mean life expectancy (about 86 years). Therefore, knee OA is a common condition in this country, representing about $15-50 \%$ of all orthopedic consultations. In Macau, the 2019 ESCEO algorithm is followed in all its steps. Regarding GS, its use was started in 1990 and now is available in different forms. Importantly, the Macau experts believe that pCGS is highly effective for knee OA symptomatology and that most old people like a simple once-daily dosage, even if many products (with different costs and effect on knee OA symptoms) are available in this country.

\section{Conclusions}

Knee OA is a signifcant problem in Southeast Asian countries, associated, similar to the rest of the world, with a high rate of disability and poor quality of life. In this paper, the WG has briefly summarized the reccomendations of the 2019 ESCEO algorithm and highlighted areas where it applies to clinical practice in Southeast Asia. Overall, the steps of the algorithm are followed and recognized as important, even if the different reimbursment criteria may change the way the algorithm is followed. This guidance provides evidence-based and easy-to-follow advice on how to establish a treatment algorithm in patients with knee OA, for practical implementation in the Southeast Asian countries' clinical practice.

Funding Open access funding provided by Università degli Studi di Palermo within the CRUI-CARE Agreement.

\section{Declarations}

Conflict of interest SSY has participated in Advisory Boards for Amgen, Eli Lilly, Mylan, Novartis and Zuellig Pharma and has had conference support from Abbvie, Celltrion, Mylan and Pfizer. HMR has received conference support form Mylan, Pfizer, Eli Lilly and Novartis. She has been in the advisory boards for Johnson \& Johnson, Novartis, Mylan, Pfizer and Eli Lilly. JKL has participated in Advisory Board for Amgen, Mylan and Zuellig Pharma and has had conference support from Amgen and Mylan. ESV has participated in Advisory Boards for Amgen, Eli Lilly, Mylan, Novartis, Jansenn and Pfizer. NV has participated in Advisory Boards for Mylan and IBSA. MYN, ES, WSC, SBC, ECP have no potential conflict of interest for this manuscript.

Ethics approval This research used already published material. The Ethics approval was not requested. 
Consent to participate (include appropriate statements)/consent for publication Not required.

Statement of human and animal rights Not required.

Open Access This article is licensed under a Creative Commons Attribution 4.0 International License, which permits use, sharing, adaptation, distribution and reproduction in any medium or format, as long as you give appropriate credit to the original author(s) and the source, provide a link to the Creative Commons licence, and indicate if changes were made. The images or other third party material in this article are included in the article's Creative Commons licence, unless indicated otherwise in a credit line to the material. If material is not included in the article's Creative Commons licence and your intended use is not permitted by statutory regulation or exceeds the permitted use, you will need to obtain permission directly from the copyright holder. To view a copy of this licence, visit http://creativecommons.org/licenses/by/4.0/.

\section{References}

1. Murray CJ, Vos T, Lozano R et al (2012) Disability-adjusted life years (DALYs) for 291 diseases and injuries in 21 regions, 1990-2010: a systematic analysis for the Global Burden of Disease Study 2010. Lancet 380:2197-2223

2. Woolf AD, Pfleger B (2003) Burden of major musculoskeletal conditions. Bull World Health Organ 81:646-656

3. Vos T, Flaxman AD, Naghavi M et al (2012) Years lived with disability (YLDs) for 1160 sequelae of 289 diseases and injuries 1990-2010: a systematic analysis for the Global Burden of Disease Study 2010. Lancet 380:2163-2196

4. Cross M, Smith E, Hoy D et al (2014) The global burden of hip and knee osteoarthritis: estimates from the global burden of disease 2010 study. Ann Rheum Dis 73:1323-1330

5. Clynes MA, Jameson KA, Edwards MH et al (2019) Impact of osteoarthritis on activities of daily living: does joint site matter? Aging Clin Exp Res 31:1049-1056

6. Beaudart $\mathrm{C}$, Biver $\mathrm{E}$, Bruyère $\mathrm{O}$ et al (2018) Quality of life assessment in musculo-skeletal health. Aging Clin Exp Res 30:413-418

7. Bruyere O, Cooper C, Pelletier JP et al (2014) An algorithm recommendation for the management of knee osteoarthritis in Europe and internationally: a report from a task force of the European Society for Clinical and Economic Aspects of Osteoporosis and Osteoarthritis (ESCEO). Semin Arthritis Rheum 44:253-263

8. Honvo G, Leclercq V, Geerinck A et al (2019) Safety of topical non-steroidal anti-inflammatory drugs in osteoarthritis: outcomes of a systematic review and meta-analysis. Drugs Aging 36:45-64

9. Honvo G, Reginster J-Y, Rannou F et al (2019) Safety of intraarticular hyaluronic acid injections in osteoarthritis: outcomes of a systematic review and meta-analysis. Drugs Aging 36:101-127

10. Cooper C, Chapurlat R, Al-Daghri N et al (2019) Safety of oral non-selective non-steroidal anti-inflammatory drugs in osteoarthritis: what does the literature say? Drugs Aging 36:15-24

11. Honvo G, Reginster J-Y, Rabenda V et al (2019) Safety of symptomatic slow-acting drugs for osteoarthritis: outcomes of a systematic review and meta-analysis. Drugs Aging 36:65-99

12. Bruyere O, Cooper C, Pelletier J-P et al (2016) A consensus statement on the European society for clinical and economic aspects of osteoporosis and osteoarthritis (ESCEO) algorithm for the management of knee osteoarthritis-From evidence-based medicine to the real-life setting. Semin Arthritis Rheum 45:S3-S11

13. Bruyère $\mathrm{O}$, Honvo $\mathrm{G}$, Veronese $\mathrm{N}$ et al (2019) An updated algorithm recommendation for the management of knee osteoarthritis from the European Society for Clinical and Economic Aspects of Osteoporosis, Osteoarthritis and Musculoskeletal Diseases (ESCEO). Semin Arthritis Rheum 49:337-350

14. Guyatt GH, Oxman AD, Vist GE et al (2008) GRADE: an emerging consensus on rating quality of evidence and strength of recommendations. BMJ 336:924

15. Zhang Z, Duan X, Gu J et al (2016) The European Society for Clinical and Economic Aspects of Osteoporosis and Osteoarthritis (ESCEO) algorithm for the management of knee osteoarthritis is applicable to Chinese clinical practice: a consensus statement of leading Chinese and ESCEO osteoarthritis experts. Chin J Pract Intern Med 36:762-772

16. Denisov L, Tsvetkova E, Golubev G et al (2016) The European Society for clinical and economic aspects of osteoporosis and osteoarthritis (ESCEO) algorithm for the management of knee osteoarthritis is applicable to Russian clinical practice: a consensus statement of leading Russian and ESCEO osteoarthritis experts. Научно-практическая ревматология Rheumatol Sci Pract 54:641-652

17. Saengnipanthkul S, Waikakul S, Rojanasthien S et al (2019) Differentiation of patented crystalline glucosamine sulfate from other glucosamine preparations will optimize osteoarthritis treatment. Int J Rheum Dis 22:376-385

18. Bruyere $\mathrm{O}$, Cooper $\mathrm{C}$, Cutolo $\mathrm{M}$ et al (2017) International endorsement of the ESCEO algorithm for management of knee osteoarthritis in clinical practice. Semin Arthritis Rheum 47:e10

19. Xia W, Cooper C, Li M et al (2019) East meets West: current practices and policies in the management of musculoskeletal aging. Aging Clin Exp Res 31:1351-1373

20. Kucharz EJ, Szántó S, Goycheva MI et al (2019) Endorsement by Central European experts of the revised ESCEO algorithm for the management of knee osteoarthritis. Rheumatol Int 39:1117-1123

21. Fernandes L, Hagen KB, Bijlsma JW et al (2013) EULAR recommendations for the non-pharmacological core management of hip and knee osteoarthritis. Ann Rheum Dis 72:1125-1135

22. Cutolo M, Berenbaum F, Hochberg M et al (2014) Commentary on recent therapeutic guidelines for osteoarthritis. Semin Arthritis Rheum 44:611-617

23. Lauche R, Langhorst J, Dobos G et al (2013) A systematic review and meta-analysis of Tai Chi for osteoarthritis of the knee. Complement Ther Med 21:396-406

24. Zhang Q, Yue J, Golianu B et al (2017) Updated systematic review and meta-analysis of acupuncture for chronic knee pain. Acupunct Med 35:392-403

25. Towheed TE, Maxwell L, Judd MG et al (2006) Acetaminophen for osteoarthritis. Cochrane Database Syst Rev CD004257

26. Zhang W, Nuki G, Moskowitz RW et al (2010) OARSI recommendations for the management of hip and knee osteoarthritis: part III: changes in evidence following systematic cumulative update of research published through January 2009. Osteoarthr Cartil 18:476-499

27. Bannuru RR, Schmid CH, Kent DM et al (2015) Comparative effectiveness of pharmacologic interventions for knee osteoarthritis: a systematic review and network meta-analysis. Ann Intern Med 162:46-54

28. Conaghan PG, Arden N, Avouac B et al (2019) Safety of paracetamol in osteoarthritis: what does the literature say? Drugs Aging $36: 7-14$

29. Lipworth L, Friis S, Mellemkjaer L et al (2003) A populationbased cohort study of mortality among adults prescribed paracetamol in Denmark. J Clin Epidemiol 56:796-801

30. McCrae J, Morrison E, MacIntyre I et al (2018) Long-term adverse effects of paracetamol-a review. Br J Clin Pharmacol 84:2218-2230

31. De Wan M, Volpi G (1998) Method of preparing mixed glucosamine salts. Google Patents 
32. Bruyère $\mathrm{O}$, Cooper $\mathrm{C}, \mathrm{Al}$-Daghri NM et al (2018) Inappropriate claims from non-equivalent medications in osteoarthritis: a position paper endorsed by the European Society for Clinical and Economic Aspects of Osteoporosis, Osteoarthritis and Musculoskeletal Diseases (ESCEO). Aging Clin Exp Res 30:111-117

33. Towheed TE, Maxwell L, Anastassiades TP, et al (2009) Glucosamine therapy for treating osteoarthritis. Cochrane Database Syst Rev CD002946

34. Reginster JY (2007) The efficacy of glucosamine sulfate in osteoarthritis: financial and nonfinancial conflict of interest. Arthritis Rheum 56:2105-2110

35. Eriksen P, Bartels EM, Altman RD et al (2014) Risk of bias and brand explain the observed inconsistency in trials on glucosamine for symptomatic relief of osteoarthritis: a meta-analysis of placebo-controlled trials. Arthritis Care Res (Hoboken) 66:1844-1855

36. Reginster JY, Deroisy R, Rovati LC et al (2001) Long-term effects of glucosamine sulphate on osteoarthritis progression: a randomised, placebo-controlled clinical trial. Lancet 357:251-256

37. Pavelka K, Gatterova J, Olejarova M et al (2002) Glucosamine sulfate use and delay of progression of knee osteoarthritis: a 3-year, randomized, placebo-controlled, double-blind study. Arch Intern Med 162:2113-2123

38. Herrero-Beaumont G, Ivorra JA, Del Carmen TM et al (2007) Glucosamine sulfate in the treatment of knee osteoarthritis symptoms: a randomized, double-blind, placebo-controlled study using acetaminophen as a side comparator. Arthritis Rheum 56:555-567

39. Bruyere O, Altman RD, Reginster J-Y (2016) Efficacy and safety of glucosamine sulfate in the management of osteoarthritis: evidence from real-life setting trials and surveys. Semin Arthritis Rheum 45:S12-S17

40. Kucharz EJ, Kovalenko V, Szanto S et al (2016) A review of glucosamine for knee osteoarthritis: why patented crystalline glucosamine sulfate should be differentiated from other glucosamines to maximize clinical outcomes. Curr Med Res Opin 32:997-1004

41. Clegg DO, Reda DJ, Harris CL et al (2006) Glucosamine, chondroitin sulfate, and the two in combination for painful knee osteoarthritis. N Engl J Med 354:795-808

42. Runhaar J, Rozendaal RM, Middelkoop MV et al (2017) Subgroup analyses of the effectiveness of oral glucosamine for knee and hip osteoarthritis: a systematic review and individual patient data meta-analysis from the OA trial bank. Ann Rheum Dis 76:1862-1869

43. Reginster JL, Bruyere O, Cooper C (2017) Different glucosamine sulfate products generate different outcomes on osteoarthritis symptoms. Ann Rheum Dis 77:e39. https://doi.org/10.1136/annrh eumdis-2017-212251

44. Bruyère $\mathrm{O}$, Reginster J-Y, Honvo G et al (2019) Cost-effectiveness evaluation of glucosamine for osteoarthritis based on simulation of individual patient data obtained from aggregated data in published studies. Aging Clin Exp Res 31:881-887

45. Volpi N (2009) Quality of different chondroitin sulfate preparations in relation to their therapeutic activity. J Pharm Pharmacol 61:1271-1280

46. Kahan A, Uebelhart D, De Vathaire F et al (2009) Long-term effects of chondroitins 4 and 6 sulfate on knee osteoarthritis: the study on osteoarthritis progression prevention, a two-year, randomized, double-blind, placebo-controlled trial. Arthritis Rheum 60:524-533

47. Zegels B, Crozes P, Uebelhart D et al (2013) Equivalence of a single dose $(1200 \mathrm{mg})$ compared to a three-time a day dose (400 $\mathrm{mg}$ ) of chondroitin $4 \& 6$ sulfate in patients with knee osteoarthritis. Results of a randomized double blind placebo controlled study. Osteoarthr Cartil 21:22-27

48. Schneider H, Maheu E, Cucherat M (2012) Symptom-modifying effect of chondroitin sulfate in knee osteoarthritis: a meta-analysis of randomized placebo-controlled trials performed with structum $((\mathrm{R}))$. Open Rheumatol J 6:183-189

49. Reginster JY, Dudler J, Blicharski T et al (2017) Pharmaceuticalgrade Chondroitin sulfate is as effective as celecoxib and superior to placebo in symptomatic knee osteoarthritis: the ChONdroitin versus CElecoxib versus Placebo Trial (CONCEPT). Ann Rheum Dis 76:1537-1543

50. Honvo G, Bruyère $\mathrm{O}$, Reginster J-Y (2019) Update on the role of pharmaceutical-grade chondroitin sulfate in the symptomatic management of knee osteoarthritis. Aging Clin Exp Res 31:1163-1167

51. Bannuru RR, Osani M, Vaysbrot E et al (2019) OARSI guidelines for the non-surgical management of knee, hip, and polyarticular osteoarthritis. Osteoarthr Cartil 27:1578-1589

52. Arden NK, Perry TA, Bannuru RR et al (2021) Non-surgical management of knee osteoarthritis: comparison of ESCEO and OARSI 2019 guidelines. Nat Rev 17:59-66

53. Rossetti L, Hawkins M, Chen W et al (1995) In vivo glucosamine infusion induces insulin resistance in normoglycemic but not in hyperglycemic conscious rats. J Clin Investig 96:132-140

54. Neil KM, Caron JP, Orth MW (2005) The role of glucosamine and chondroitin sulfate in treatment for and prevention of osteoarthritis in animals. J Am Vet Med Assoc 226:1079-1088

55. Muniyappa R, Karne RJ, Hall G et al (2006) Oral glucosamine for 6 weeks at standard doses does not cause or worsen insulin resistance or endothelial dysfunction in lean or obese subjects. Diabetes 55:3142-3150

56. Dostrovsky N, Towheed T, Hudson R et al (2011) The effect of glucosamine on glucose metabolism in humans: a systematic review of the literature. Osteoarthr Cartil 19:375-380

57. Runhaar J, Deroisy R, van Middelkoop M et al (2016) The role of diet and exercise and of glucosamine sulfate in the prevention of knee osteoarthritis: further results from the prevention of knee osteoarthritis in overweight females (PROOF) study. Semin Arthritis Rheum 45(4 Suppl):S42-S48

58. Gommans YM, Runhaar J, Jacobs ML et al (2017) The effect of prolonged glucosamine usage on HbA1c levels and new-onset diabetes mellitus in overweight and obese middle-aged women. Am J Med 130:e736

59. Veronese N, Cooper C, Reginster J-Y et al (2019) Type 2 diabetes mellitus and osteoarthritis. Semin Arthritis Rheum 49:9-19

60. Palleria C, Di Paolo A, Giofrè C et al (2013) Pharmacokinetic drug-drug interaction and their implication in clinical management. J Res Med Sci 18:601

61. Gallelli L, Galasso O, Falcone D et al (2013) The effects of nonsteroidal anti-inflammatory drugs on clinical outcomes, synovial fluid cytokine concentration and signal transduction pathways in knee osteoarthritis. A randomized open label trial. Osteoarthr Cartil 21:1400-1408

62. Burkhard K, Shapiro P (2010) Use of inhibitors in the study of MAP kinases. MAP kinase signaling protocols. Springer, Berlin, pp 107-122

63. Cepeda MS, Camargo F, Zea C et al (2006) Tramadol for osteoarthritis. Cochrane Database Syst Rev CD005522

64. Pelletier JP, Martel-Pelletier J, Rannou F et al (2016) Efficacy and safety of oral NSAIDs and analgesics in the management of osteoarthritis: Evidence from real-life setting trials and surveys. Semin Arthritis Rheum 45:S18-S21

65. Fuggle N, Curtis E, Shaw S et al (2019) Safety of opioids in osteoarthritis: outcomes of a systematic review and meta-analysis. Drugs Aging 36:129-143

66. Bruyere O, Ethgen O, Neuprez A et al (2012) Health-related quality of life after total knee or hip replacement for osteoarthritis: a 7-year prospective study. Arch Orthop Trauma Surg 132:1583-1587 
67. Ethgen O, Bruyere O, Richy F et al (2004) Health-related quality of life in total hip and total knee arthroplasty. A qualitative and systematic review of the literature. J Bone Jt Surg Am 86:963-974

68. Shan L, Shan B, Suzuki A et al (2015) Intermediate and long-term quality of life after total knee replacement: a systematic review and meta-analysis. J Bone Jt Surg Am 97:156-168

69. Nuesch E, Rutjes AW, Husni E et al (2009) Oral or transdermal opioids for osteoarthritis of the knee or hip. Cochrane Database Syst Rev CD003115

70. Manchikanti L, Kaye AM, Knezevic NN et al (2017) Responsible, safe, and effective prescription of opioids for chronic non-cancer pain: american society of interventional pain physicians (ASIPP) guidelines. Pain Phys 20:S3-S92

71. Veerapen K, Wigley RD, Valkenburg H (2007) Musculoskeletal pain in Malaysia: a COPCORD survey. J Rheumatol 34:207-213

Publisher's Note Springer Nature remains neutral with regard to jurisdictional claims in published maps and institutional affiliations.

\section{Authors and Affiliations}

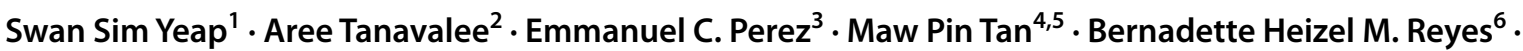 Joon Kiong Lee ${ }^{7}$. Mohd Yahaya Norhamdan ${ }^{8}$. Evan S. Vista ${ }^{9}$. Wai Sin Chan ${ }^{10}$. Sy Bui Cong ${ }^{11}$.} Pham Thi Thanh Tam ${ }^{12} \cdot$ Jean-Marc Kaufman ${ }^{13} \cdot$ Jean-Yves Reginster ${ }^{14,15,16} \cdot$ Nicola Veronese $^{17}\left(\mathbb{0} \cdot\right.$ Ester Penserga $^{18}$

1 Department of Medicine, Subang Jaya Medical Centre, Subang Jaya, Selangor, Malaysia

2 Department of Orthopaedics, Vinai Parkpian Orthopaedic Research Center, Faculty of Medicine, King Chulalongkorn Memorial Hospital, Thai Red Cross Society, Chulalongkorn University, Bangkok 10330, Thailand

3 College of Medicine De La Salle Medical Health Science Institute (DLSMHSI), Dasmariñas, Cavite, Philippines

4 Ageing and Age-Associated Disorders Research Group, Department of Medicine, Faculty of Medicine, University of Malaya, Kuala Lumpur, Malaysia

5 Department of Medical Sciences, Faculty of Healthcare and Medical Sciences, Sunway University, Bandar Sunway, Malaysia

6 Department of Medicine, Philippine General Hospital-University of the Philippines College of Medicine, Manila, Philippines

7 Department of Orthopedic Surgery, Beacon Hospital, Petaling Jaya, Malaysia

8 Department of Orthopaedics and Traumatology, Faculty of Medicine, Universiti Kebangsaan Malaysia, Kuala Lumpur, Malaysia

$9 \quad$ Rheumatology, Allergy and Immunology Center, St. Luke's Medical Center, Manila, Philippines
10 Orthopaedic Surgeon of Orthopaedic Department of Centro Hospitalar Conde de Sao Januario, Macao, China

11 Department of Rheumatology, 103 Military Hospital, Hanoi, Vietnam

12 Rheumatology Department of 30-4 Hospital, Ho Chi Minh City, Vietnam

13 Department of Endocrinology, State University of Ghent, Ghent, Belgium

14 Public Health, Epidemiology and Health Economics Department, ULiège, Liège, Belgium

15 Chair for Biomarkers of Chronic Diseases, Biochemistry Department, College of Science, King Saud University, Riyadh, Kingdom of Saudi Arabia

16 Centre Académique de Recherche Et D’Expérimentation en Santé (CARES SPRL), Liège, Belgium

17 Geriatric Unit, Department of Internal Medicine and Geriatrics, University of Palermo, V.le F. Scaduto 61, 90144 Palermo, Italy

18 College of Medicine University of the Philippines, Manila, Philippines 